\title{
Synthesis and Characterization of Platinum Nanoparticle Catalysts Capped with Isolated Zinc Species in SBA-15 channels: the Wall Effect
}

\author{
Elizabeth Raine $\ddagger_{\dagger}$, Adam H. Clark $\|+$, Glen Smales $\|$, Andrew Smith $\perp$, Diego Gianolio $\_$, Tong Lis, \\ Jianwei Zheng‡, Benjamin E. Griffith $\nabla$, Tim I. Hyde\%, Mark Feaviour\%, Paul Collier\%, John V. \\ Hanna $\nabla$, Gopinathan Sankar\| and Shik Chi Edman Tsang ${ }^{*}$. \\ ‡ Wolfson Catalysis Centre, Department of Chemistry, University of Oxford, Oxford, OX1 3QR, UK. \\ ॥ Department of Chemistry, University College London, 20 Gordon Street, WC1E 0AJ, London, UK. \\ $\perp$ Diamond Light Source Ltd, Harwell Science and Innovation Campus, Didcot, Oxfordshire, OX11 0DE, UK \\ § Institute for Materials \& ZGH, Ruhr-Universität Bochum, Universitätsstr. 150, 44801 Bochum, Germany \\ $\nabla$ Department of Physics, University of Warwick, Coventry, CV4 7AL, United Kingdom \\ \% Johnson Matthey, Blount's Court, Sonning Common, Reading, RG4 9NH,UK
}

† First author with equal contribution.

KEYWORDS (Nanoparticle, SBA-15, Single atom, Decoration. Support, wall effect, catalyst).

\begin{abstract}
The strong directing effects and difficulties in the removal of organic based surfactants makes the templated synthesis of nanoparticles in solid porous structures of defined molecular sizes such as SBA-15, without the use of surfactants, considerably attractive. However, the effects of their internal surface structures, adsorption affinities and lattice mismatch on the particle morphology grown therein have not been fully appreciated. Here, we report the internal surface of the silica preferentially hosts isolated tetrahedrally coordinated oxidic Zn species on the molecular walls of the SBA-15 channels from wet impregnated $\mathrm{Zn}_{2+}$ and $\mathrm{Pt}_{2+}$ species. This leads to less thermodynamic stable but kinetic controlled configuration of atomic zinc deposition on core platinum nanoparticles with unique confined lattice changes and surface properties to both host and guest structures at the interface upon reduction of the composite. This method for the formation templated nanoparticles may generate interests to form new tunable materials as dehydrogenation catalysts.
\end{abstract}

With increasing world population 1 , diminishing access to fossil fuel reserves 2 and a rapidly developing world, the need for new or more efficient routes of energy and chemicals provisions has never been more vital.3 Tailoring catalyst structures and surfaces for specific chemical reactions to improve catalytic efficiencies is continuously of interest to the catalysis community. Many bimetallic catalysts have recently been found to show superior activity or selectivity than their monometallic counterparts due to surface site blocking and electronic modulation. 4,5 For example, bimetallic nanoparticles containing platinum are often used in catalytic reactions with low activation barriers and enhanced activity or selectivity.6 Platinum zinc species are reported to be active for hydrogenation and dehydrogenation reactions.7-9

However, size control in bimetallic nanoparticles is commonly achieved in the presence of surfactants or polymers which may impair working catalysts and are not easy to remove for most catalytic applications. 10 There are some recently reported surfactant-free syntheses methods in catalyst preparation.11-14 Synthesis of these bimetallic nanoparticles inside thermally stable porous structures as supports, without separating the templates, perhaps represents one of the most attractive methods. 15,16

Supported nanoparticles have been well researched along with the introduction of the smallest particle possible, single-atom catalysts.17-19 Surface decoration by single atoms on monometallic particles are anticipated to give high catalytic performances.20-22 For example, it has been seen that zinc deposited on a copper nanoparticle has increased catalytic ability with enhanced formate binding. 23

One method of synthesizing single isolated sites is through the use of ion-exchange Bronsted proton of $\mathrm{Al}$ sites in zeolites. It has been seen that $\mathrm{Zn}^{2+}$ species can be exchanged with the protonic sites in the zeolite surface leaving isolated $\mathrm{Zn}$ ions immobilized in the zeolite walls.24,25 The introduction of these dopant ions into the zeolite walls can lead to the formation Lewis acid sites.24,26 The nature of these acidic sites can depend on the synthesis method, as well as the dopant type and concentration. Various methods of binding $\mathrm{Zn}^{2+}$ onto the surfaces of zeolites and silicas have been discussed, many proposing a tetrahedral coordinated species with the 
surface oxygens binding to the $\mathrm{Zn}^{2+}$, allowing it to be capped by other reagents.25,27 These zinc modified zeolites have been shown to have enhanced catalytic behaviour for methane activation as well as propylene hydrogenation.28,29 Further investigation was performed on zincosilicate CIT-6 leading to enhanced Diels-Alder reactivity which was not previously possible with alternative dopants.30 However, the small size of internal cavities of zeolites do not allow the synthesis of metal nanoparticles to be decorated with these isolated species.

There has been a previous attempt utilising the mesoporous channels of SBA-15 silica as a porous support to promote a core-shell growth of $\mathrm{AgNi}$ particles 31 without the use of a surfactant. The 1-dimensional channels not only restrict the particle growth ensuring a small particle size distribution, but are thought to encourage the two metal precursors to grow separately forming a phase boundary under mild reduction temperatures as benign hosts. The core and shell thickness can be tuned by using different precursor ratios. The incorporation of $\mathrm{Ni}$ to $\mathrm{Ag}$ particles of defined particle size may generate new catalysts for selective hydrogenation.32-34 It is, however, the effects of the internal surface structure of SBA-15, surface affinities and lattice mismatches on the metallic particle morphology grown therein and vice versa to the SBA-15 host structure have not been fully appreciated. A literature review in advances in the use of SBA-15 as a nanoparticle support, catalyst and adsorbent can be found in Table S1.

Here, we report the synthesis of the PtZn bimetallic system in SBA-15 channels using the same methodology. Instead of obtaining thermodynamic more stable Pt-Zn core-shell or their homogeneous alloy structure, it is interesting to see the surface atomic doping of $\mathrm{Zn}$ atoms on the core Pt nanoparticles with kinetic controlled lattices at the materials interface, in this porous template after mild reduction, as shown by Figure 1 . We attribute this interesting observation to the high affinity of silica walls as the main influencing factor for hosting $\mathrm{Zn}^{2+}$, allowing preferential homogeneous wetting on silica internal surface during preparation, presumably due to comparable bonding environment and hydrophilic properties.

Figure 1. A schematic to show the synthesis procedure and resulting supported nanoparticles. Aqueous $\mathrm{Zn}^{2+}$ and $\mathrm{Pt}^{4+}$ are impregnated into the SBA-15, followed by reduction, yielding highy isolated $\mathrm{Zn}$ ions across the surface of the SBA-15 walls and Pt nanoparticles in the channels. Some $\mathrm{Zn}$ species are found on the $\mathrm{Pt}$ surface although some remain isolated and do not form a full shell.

In addition, the structural mismatches of host and guest can also affect their final lattice parameters, giving the fundamental basis for new catalytic properties of the composites. Thus, we also show that the effects on the porous template structure in molecular dimensions, internal surface structure and chemical affinity play important roles to the growth of nanoparticles therein and could not be ignored. It is anticipated that the rationalizations may be further developed as a new synthesis method for atomic deposition of metal nanoparticles within porous template structures.

\section{Results and discussion}

Platinum zinc of differing compositions $\left(\mathrm{Pt}_{2} \mathrm{Zn}_{8}, \mathrm{Pt}_{5} \mathrm{Zn}_{5}\right.$, $\mathrm{Pt}_{8} \mathrm{Zn}_{2}$ ) along with monometallic $\mathrm{Pt}$ and $\mathrm{Zn}$ were synthesized without the use of surfactants within the 1dimensional channels of the mesoporous silica support, SBA-15, in order to encourage small nanoparticle growth therein. These bimetallic PtZn/SBA-15 particles after reduction, along with the $\mathrm{Zn} / \mathrm{SBA}-15$ and $\mathrm{Pt} / \mathrm{SBA}-15$ monometallic comparison samples, are extensively characterized by Transmission Electron Microscopy (TEM), Low Energy Ion Scattering (LEIS), X-Ray Absorption Spectroscopy (XAS), Wide Angle X-ray Scattering (WAXS), Small Angle X-ray Scattering (SAXS) and Atom Probe Tomography (APT) for a full structural and spatial understanding.

Transmission Electron Microscopy (TEM) images were taken of the samples prepared through the reported synthesis in order to confirm the nanoparticle formation inside the silica channels and ensure no larger particles were aggregating on the silica surface. To control the particle size and distribution of the two metals, the particles must form inside the channels rather than on the external silica surface. Figure A, which shows the particles are well distributed inside the SBA-15 channels and with no larger aggregated particles on the outside of the porous silica. This was confirmed by secondary electron imaging, Figure $2 \mathrm{C}$, showing that there are no particles on the surface of the silica in the same region where particles are seen in the bright field image, Figure $2 \mathrm{~B}$. The $\mathrm{Pt}_{2} \mathrm{Zn}_{8} / \mathrm{SBA}-15$ nanoparticles have a mean diameter of $4.2 \mathrm{~nm}( \pm 1.9 \mathrm{~nm})$, which is narrower than the average SBA-15 channel diameter of $6.5 \mathrm{~nm}$ (S1) meaning that the channels are not blocked for any reactants. This is also valid for the $\mathrm{Pt}_{5} \mathrm{Zn}_{5} / \mathrm{SBA}-15$ and the $\mathrm{Pt}_{8} \mathrm{Zn}_{2} / \mathrm{SBA}-15$ which have mean diameters of $3.2 \mathrm{~nm}( \pm 2.3 \mathrm{~nm})$ and $3.1 \mathrm{~nm}( \pm 1.5 \mathrm{~nm})$ respectively (S2\&S3). Pt/SBA-15 nanoparticles show a similar particle size of $3.1 \mathrm{~nm}( \pm 1.5 \mathrm{~nm})$ (S4). Interestingly, in the direct comparison with $\mathrm{Pt}$ nanoparticles, no particles or areas of material aggregation could be seen in the $\mathrm{Zn} / \mathrm{SBA}-15$ sample, indicating much smaller $\mathrm{Zn}$ species were present (Figure 3), indicative of the strong wetting properties of silica walls towards $\mathrm{Zn}$ species.

Scanning EDX was performed in conjunction with the secondary electron imaging in order to understand the elemental distribution of these samples. Figure 2 D, E \& F shows the presence of both platinum and zinc in the nanoparticles, with zinc located fully across the silica support, indicating the zinc spreads across the walls of the silica rather than being only deposited at the platinum particles. The higher density regions of zinc near the platinum suggest that there is a favourable interaction between the zinc and the platinum with platinum particles capped with zinc species on the silica surface (see further TEM and EDX in S1-S5). 
Figure 2. A) TEM image of Pt2Zn8/SBA-15. B) Bright field image of Pt2Zn8/SBA-15. C) Corresponding secondary electron image. D) Scanning EDX data from Pt2Zn8/SBA-15 sample with E) EDX map of Zn distribution and F) EDX map of Pt distribution.

Figure 3. TEM image at 40K magnification of A) $\mathrm{Zn} / \mathrm{SBA}-15$ and B) Pt/SBA-15

Low Energy Ion Scattering (LEIS) was used to identify the elemental composition of $\mathrm{Pt}_{2} \mathrm{Zn}_{8} / \mathrm{SBA}-15$ sample at various particle depths by stripping its surface with high energetic $\mathrm{Ne}^{+}$. Error! Reference source not found.S6A shows that the first scan of $0.06 \mathrm{~nm}$ correlating to the surface of the silica channels where mainly $\mathrm{Zn}$ is present, with only a very small Pt quantity. There is a dramatic increase in Pt intensity as the depth increases to $3.9 \mathrm{~nm}$. According to our peaks fitted with average spherical particles, it is clear that the Pt intensity is much increased on probing deeper into the particle, Error! Reference source not found.S6B. Thus, the high zinc content in the first scan indicates that there is zinc enrichment at the surface of the SBA-15 channels. After removal of the silica surface and zinc, the platinum becomes more prominent, the zinc signal remains intense due to the zinc across the surface of the SBA-15 channel. This result is consistent with the EDX result, showing the surprisingly enrichment of zinc content on the silica walls. Only the $\mathrm{Pt}_{2} \mathrm{Zn}_{8} / \mathrm{SBA}-$ 15 sample was tested for such analysis to illustrate that $\mathrm{Zn}$ is primarily at the surface of the Pt particle. However, the segregation in metal distribution in the particle with other compositions has also been shown with other characterisation techniques in this paper. The elemental phase segregation was also proved previously in our other systems in SBA-15. 31

X-ray Absorption Spectroscopy (XAS) on the Zn K-edge was used to further investigate the structure of the zinc in the silica walls. The $\mathrm{Zn} \mathrm{K}$-edge XANES shows a different profile to many standard zinc salts tested as shown in

Figure $4 \mathrm{~A}$ indicating that the formation of a common salt is not occurring. Indeed, the best agreement of the $\mathrm{Zn} / \mathrm{SBA}-15$ experimental spectra is with modelled isolated zinc tetrahedra from FDMNES35,36 modelling calculations, as shown in

Figure 4C. This suggests that the zinc is bonded to the silica walls forming isolated tetrahedrally coordinated oxidic species. Instead of getting the extended tetrahedral sharing units of $\mathrm{ZnO}, \mathrm{Zn}(\mathrm{OH})_{2}$ or related bulk solid structures, these $\mathrm{Zn}-\mathrm{O}$ tetrahedra are clearly isolated zinc species as shown by the absence of long-range order in the EXAFS region with no $\mathrm{Zn}-\mathrm{Zn}$ interactions (S8).

Figure4B shows that on increasing the zinc content in the Pt$\mathrm{Zn} / \mathrm{SBA}-15$ series, the white line intensity decreases and the peak splits into a strong doublet which agrees with the results which have been previously reported by Mei et al. who attributed the formation of $\left[\mathrm{ZnO}_{4}\right]^{6-}$ on silica surfaces. 37 The similarity in lattice and coordination number matching with internal silica surface appears to offer a strong directing role to bind $\mathrm{Zn}$ ions preferentially from the mixture of $\mathrm{Pt}$ and $\mathrm{Zn}$ precursors.

Figure 4. A) A comparison of measured $\mathrm{Zn}$ standard materials and the $\mathrm{Zn}$ isolated tetrahedron result of the FDMNES calculation. B) Zn K-edge XANES plot of the Zn/SBA-15 and PtZn/SBA-15 series from B18 at Diamond Light Source. C) A direct comparison of the experimental Zn/SBA-15 Zn K-edge XANES spectrum measured and the FDMNES calculated spectra for $\mathrm{Zn}$ isolated tetrahedron.

Analysis of the $\mathrm{Zn} \mathrm{K}$ edge EXAFS demonstrates there is no long range ordered structure present in the local coordination environment of the $\mathrm{Zn}$ atoms. Fitting to the EXAFS has been performed using the Demeter software package. The amplitude reduction factor was determined by fitting to a $\mathrm{ZnO}$ standard material. The Fourier Transform range used was $2.4-9.7 \AA^{-1}$ and the fitting was performed in $\mathrm{R}$ space. A $\mathrm{Zn}-\mathrm{O}$ scattering path was fitted with all parameters free with the results shown in Table S2. Example fitting to the $\mathrm{Zn} / \mathrm{SBA} 15$ sample are shown in figure S7, remaining figures for all samples are shown in figures S16-17. The fitting results demonstrate that in all samples $\mathrm{Zn}$ is found to be present in isolated oxidic tetrahedral with no ordered extended local structure suggesting a disordered binding to the silica wall.

The platinum structure and electronic properties were also investigated with XAS on the $\mathrm{Pt} \mathrm{L}_{3}$-edge. The XANES shows that there is a combination of both the metallic and a small amount of oxidic phase in the platinum particles in the structure after reduction, Figure 5. The pure Pt/SBA-15 sample shows the most metallic nature with a higher oxide component when zinc is introduced into the system, although this oxidic nature does not continue to increase on increasing the zinc content. The exact fraction of the oxidic component in the PtZn/SBA-15 samples is not yet known as the particle size effects of metal clusters on the XANES spectrum make the linear combination fitting not possible $38-41$.

\section{A}

Figure 5.A) $\mathrm{Pt}_{3}$-edge XANES comparison of the standard Pt materials, platinic acid and metallic Pt, with B) the Pt/SBA15 and three PtZn/SBA-15 materials.

Analysis of the $\mathrm{Pt}_{3}$ edge EXAFS has been performed to determine the average local structure around the absorbing Pt atoms, the results are shown in Table S3. Fitting was performed using a Fourier transform range of $\mathrm{K} 2.8-10.8 \AA^{-1}$ allowing for refinement of Pt-Pt and Pt-O coordination shells associated to oxide and metallic components. The amplitude reduction factor was determined through fitting performed over the aforementioned $\mathrm{K}$ range to a $\mathrm{Pt}$ metal foil reference data using the Demeter software package. During refinement the Pt-O bond distance and $\sigma^{2}$ parameters where held fixed 
from an initial refinement performed on the $\mathrm{Pt}_{2} \mathrm{Zn}_{8} / \mathrm{SBA}$ 15 (most oxidic) sample due to high correlation with the coordination number. The $\sigma^{2}$ parameter for the $\mathrm{Pt}-\mathrm{Pt}$ coordination shell was refined from the Pt/SBA-15 sample (most metallic) and held constant for the remaining samples. From this analysis a clear trend can be observed, with decreasing $\mathrm{Pt}$ content there is a decreasing proportion of $\mathrm{Pt}$ than is found in metallic state. Example fitting is shown in figure $\mathrm{S} 8$ for the $\mathrm{Pt}_{8} \mathrm{Zn}_{2} / \mathrm{SBA}-15$ sample, remaining samples are shown in figures S14-15. From these results it is proposed that the Pt exists as a metallic nanoparticle with a oxide surface shell. By assuming a spherical nanoparticle model it is possible to obtain an estimate for the metallic Pt core diameter: $2.6 \mathrm{~nm}, 1.4 \mathrm{~nm}$, $1.5 \mathrm{~nm}$ and $1.2 \mathrm{~nm}$ respectively in order of highest $\mathrm{Pt}$ content.

Wide Angle X-ray Scattering (WAXS) was used to analyse the crystalline structural component in the samples. It can be seen in Figure 6 that each platinum containing sample has reflection peaks which correspond well to the known metallic platinum crystal structure of $3.924(2) \AA$ (red) but with slight smaller lattice parameter of 3.890(1) A. This confirms the extended crystalline metallic structural phase of the Pt/SBA-15 but the slight small lattice is thought to be due to the distortion of $\mathrm{Pt}$ on the porous silica template internal surface. In contrast to XAS, no oxidic platinum phase is observed by this technique which indicates that this phase is particularly small or noncrystalline. Additionally, there are no crystalline peaks in the $\mathrm{Zn} / \mathrm{SBA}-15$ sample, confirming the high dispersion of the isolated zinc species likely in the silica walls rather than the presence of oxidic $\mathrm{Zn}$ or $\mathrm{Zn}$ containing particles. The gradual decrease in peak intensity down the patterns is indicative of the decreasing Pt content in the samples leading to decreased crystallinity and particle size. As the Pt content decreases, there is also a small but progressive shift to higher Q space, indicating a further contraction of lattice parameter. This shift correlates to a face centered cubic lattice parameter decrease from 3.890(1) $\AA$ for Pt/SBA-15 to 3.830(1) $\AA$ for $\mathrm{Pt}_{2} \mathrm{Zn}_{8} / \mathrm{SBA}-15$. Thus, we attribute the main change in lattice parameter to the inclusion of zinc decoration on the Pt nanoparticles.

Figure 6. Stacked figure showing the WAXS obtained on each sample with a metallic Pt phase shown in red below for comparison illustrating the Bragg diffraction peaks are synonymous to metallic $\mathrm{Pt}$ or $\mathrm{PtZn}$ particles within the SBA15 channels.

Small Angle X-ray Scattering (SAXS) was also used to investigate the changes in SBA-15 support lattice in revers manner upon the introduction of the metals. Error! Reference source not found.S9a shows the Bragg reflections from the stacking of the SBA-15 in each sample. All samples show the same hexagonal structure as the bare support (black), however there is seen to be some peak splitting in the samples containing the Pt particles. This is due to a change in lattice parameter in some of the SBA-15 after introduction of the metal particles. Fitting of the (200) reflection was accomplished using a two-peak fitting model with the resultant lattice parameters being derived by consideration of the Bragg scattering from a hexagonal lattice structure with an infinite pores along the c axis, example fitting is shown in Error! Reference source not found.S9b. The fraction of distorted SBA-15 is given in Error! Reference source not found. 4 where the maximum distortions are observed for $\mathrm{Pt}_{5} \mathrm{Zn}_{5} / \mathrm{SBA}-15$ and $\mathrm{Pt}_{2} \mathrm{Zn}_{8} / \mathrm{SBA}-15$ with the alteration in lattice parameter $\left(\mathrm{a}_{2}\right)$ fraction of approximately $31-32 \%$.

McSAS fitting has been employed to analyse the particle size distribution within the SBA-15 samples $^{42}$ Here the Bragg reflections have been removed from fitting. Figure 8 gives the size distribution present exhibiting two clear features. The first relating to the Pt particles within the SBA-15 pores and the second to the SBA-15 pores. There is no result given for the $\mathrm{Zn} / \mathrm{SBA}-15$ sample as this failed to converge and no clear crystalline particles due to $\mathrm{Zn}$ are expected to be observed.

5 gives the average $\mathrm{Pt}$ particle diameter and average SBA-15 pore diameter results. Here there is an observed trend in the Pt particle size dependant on the atom fraction of Pt within each sample, with larger particles observed with increased Pt content. It is interesting to note that the pore diameter of SBA-15 is also greatly distorted from 6.0 $\mathrm{nm}$ to $5.4 \mathrm{~nm}$ in the $\mathrm{Pt}_{5} \mathrm{Zn}_{5} / \mathrm{SBA}-15$ and $\mathrm{Pt}_{2} \mathrm{Zn}_{8} / \mathrm{SBA}-15$ samples, presumably due to the presence of the large crystalline $\mathrm{Pt}$ and the amorphous $\mathrm{Zn}$ coating.

In restricted geometries, substrate molecules can interact with internal wall surfaces strongly through hydrophobic and hydrophilic interactions with or without hydrogen-bond interactions. This may lead to high activity and selectivity towards catalytic reactions of particular substrate molecules. It is noted that the partial ordering of the water molecules has been reported in the vicinity of the confining surfaces, such as in zeolites or cements, or water molecules in hydration shells of proteins.43 Specifically, the existence of different kinds of water in pores, free water in the center of the pore and bound water near the pore surface, has been previously established by a variety of experimental techniques.43 Analyzing these structures may help in the understanding of the hydrophilic or hydrophobic-surface interaction at the molecular level.

The solid state ${ }^{29} \mathrm{Si},{ }^{1} \mathrm{H}$ and ${ }^{195} \mathrm{Pt}$ NMR data measured from the suite of samples is exhibited in Figure 7 and reported in Table 1. All deconvoluted and simulated ${ }^{29} \mathrm{Si}$ MAS NMR data shown in Figure 7a and Figure S11 clearly indicate that the $\mathrm{Q}^{\mathrm{n}} \mathrm{Si}$ speciation defining the SBA-15 silicate network is described by $\mathrm{Si}(\mathrm{OSi})_{\mathrm{n}} \mathrm{O}(\mathrm{R})_{4-\mathrm{n}}($ with $\mathrm{R}=$ $\mathrm{Zn}$ or $\mathrm{H}$ ) and is represented by $\mathrm{Q}^{2}, \mathrm{Q}^{3}$ and $\mathrm{Q}^{4}$ species with the corresponding ${ }^{29} \mathrm{Si}$ resonances observed at $\delta \sim 91, \sim 102$ and $\sim 110 \mathrm{ppm}$, respectively. As expected for the mesoporous SBA-15 sample, the network is dominated by $\mathrm{Q}^{4}$ units comprising $\sim 84 \%$ of the total $\mathrm{Si}$ speciation, with $\mathrm{Q}^{3}(\sim 12 \%)$ and $\mathrm{Q}^{2}(\sim 4 \%)$ species constituting minor components. A useful parameter elucidated from the quantitative ${ }^{29} \mathrm{Si}$ MAS NMR data used to describe network alteration upon the incorporation of network forming and/or network modifying cations is the network 
connectivity $(\mathrm{NC})$ defined by: $\mathrm{NC}=\left(\mathrm{Q}^{1} \%+2 \mathrm{Q}^{2} \%+3 \mathrm{Q}^{3} \%\right.$ $\left.+4 \mathrm{Q}^{4} \%\right) / 4.44-47$

Previous studies of $\mathrm{Zn}$ incorporation into biomaterial and glass formulations have demonstrated that $\mathrm{Zn}$ exhibits both network forming and network modifying characteristics;48-50 elements of this behaviour able to be identified upon $\mathrm{Zn}$ incorporation into the SBA-15 network.

From the incorporation of $\mathrm{Zn}$ to form the $\mathrm{Zn} / \mathrm{SBA}-15$ sample, it can be observed from the ${ }^{29} \mathrm{Si}$ MAS NMR data of Figure $7 \mathrm{a}$ and integrated intensities in Table 1 that the relative populations of the $\mathrm{Q}^{3}$ species increases by $\sim 18 \%$ and NC drops from 3.81 to 3.62 in comparison to the native SBA-15 system. Hence, the $\mathrm{Zn}^{2+}$ cation causes significant network modification and a concomitant increase in the non-bridging $\mathrm{O}$ bond $(\mathrm{Si}=\mathrm{O} \cdots \mathrm{Zn})$ formation. The corresponding ${ }^{1} \mathrm{H}$ MAS data (see Figure $7 b$, Table S6) exhibits large changes to the nature of the $\mathrm{H}$ network on the SBA-15 surface. While the native SBA-15 system exhibits well resolved $-\mathrm{OH}$ resonances in the range $\delta 0.6$ $1.6 \mathrm{ppm}$ (isolated surface silanol $\mathrm{Si}-\mathrm{OH}$ species with no nearby ${ }^{1} \mathrm{H}$ species to promote $\mathrm{H}$-bonding), at $\delta 3.5 \mathrm{ppm}$ (isolated surface silanol $\mathrm{Si}-\mathrm{OH}$ species with $\mathrm{H}$ bonding/proximity to small residual non-bridging $\mathrm{O}$ components), and physisorbed $\mathrm{H}_{2} \mathrm{O}$ represented by resonances in the range $\delta 5.0-6.0 \mathrm{ppm}$, the ${ }^{1} \mathrm{H}$ MAS NMR data from $\mathrm{Zn} / \mathrm{SBA}-15$ system suggests a more strongly $\mathrm{H}$ bonded system characterized by much broader resonances. In this latter case, $\mathrm{Zn}$ incorporation has markedly increased the population of network modified non-bridging $\mathrm{Si}=\mathrm{O} \cdots \mathrm{Zn}$ species, thus driving the majority of the $-\mathrm{OH}$ species into a $\mathrm{H}$-bonded network with non-bridging $\mathrm{O}$ species as evidenced by the broad dominant ${ }^{1} \mathrm{H}$ resonance at $\delta \sim 3.7 \mathrm{ppm}$. Furthermore, the wettability of the $\mathrm{Zn}$ modified Zn/SBA-15 surface has increased as evidenced by the greater intensity of the $\mathrm{H}_{2} \mathrm{O}$ resonance at $\delta \sim 6.0 \mathrm{ppm}$ suggesting a higher affinity for physisorbed $\mathrm{H}_{2} \mathrm{O}$. In this case, the broader ${ }^{1} \mathrm{H}$ linewidth and more downfield ${ }^{1} \mathrm{H}$ chemical shift of the $\mathrm{H}_{2} \mathrm{O}$ resonance indicates increased $\mathrm{H}$ bonding within clusters of surface $\mathrm{H}_{2} \mathrm{O}$ molecules with less mobility51. The large increase in the $\mathrm{Q}^{3} \mathrm{Si}$ species, together with the loss of the majority of the surface silanol $(\mathrm{Si}-\mathrm{OH})$ species and the increase of $\mathrm{OH}$ which are $\mathrm{H}$ bonded to network modified structures (such as nonbridging $\mathrm{O}$ ) suggests that the $\mathrm{Zn}$ incorporation is not confined strictly to the SBA-15 surface, but creates a substitution of Si into the bulk structure.

In contrast, the incorporation of $\mathrm{Pt}$ towards the formation of the analogous Pt/SBA-15 system induces very different response from the SBA-15 surface and bulk speciation. The ${ }^{29} \mathrm{Si}$ MAS NMR data of Figure 7a suggests that the introduction of $\mathrm{Pt}$ also causes more modest network modification as evidenced by the increased intensity $\mathrm{Q}^{3}$ resonances by $\sim 10 \%$ and a reduction of $\mathrm{NC}$ from to 3.65 (see Table 1). Although there is some evidence of $\mathrm{H}$-bonded $-\mathrm{OH}$ species to non-bridging $\mathrm{O}$ species through network modification from the broader $\delta$ $\sim 3.8$ ppm resonance in the ${ }^{1} \mathrm{H}$ MAS NMR data, this contribution is very much reduced in comparison to that observed in the $\mathrm{Zn} / \mathrm{SBA}-15$ system, with most of the surface $\mathrm{H}$ speciation remaining unperturbed from that characterizing the native SBA-15. This suggests that most of the network modification induced by Pt incorporation is confined to the surface, and that the majority of $\mathrm{Q}^{3}$ involve $\mathrm{Si}-\mathrm{O}-\mathrm{Pt}$ linkages which tether $\mathrm{Pt}$ nanoparticle formation to the SBA-15 surface, or non-bridging $\mathrm{O}$ structures to form these linkages.

The ${ }^{29}$ Si MAS NMR data for the Pt-Zn/SBA-15 series (see Figure 7a and Table 1) exhibits the largest amount of network modification with (on average) $\sim 33 \%$ of the observed Si speciation now assuming a $\mathrm{Q}^{3}$ identity.

From the NMR data, it is therefore evident that $\mathrm{Zn}^{2+}$ has a stronger affinity to substitute the $\mathrm{Si}^{4+}$ than $\mathrm{Pt}^{2+}$, the effect of which can go beyond the top surface to the interior of the SBA-15 wall structure. It is interesting to note that the higher $\mathrm{Zn}$ content samples such as Zn/SBA-15 and $\mathrm{Pt}_{5} \mathrm{Zn}_{5} / \mathrm{SBA}-15$ display a broad resonance at a chemical shift value of 3.4-3.6ppm and 5.0-6.0ppm of water clusters, indicative that the $\mathrm{Zn}$ modified surfaces have a higher affinity for water (high mobility of hydroxyl units for chemical exchange)51 than that of hydrophobic $\mathrm{Pt}$ modified surfaces with hydroxyl units of less mobility. The $\mathrm{Pt}_{2} \mathrm{Zn}_{8} / \mathrm{SBA}-15$ is anticipated to display similar affinity for water although this sample had been extensively dried before the measurement.

The ${ }^{195} \mathrm{Pt}$ static NMR data from the $\mathrm{Pt}_{8} \mathrm{Zn}_{2} / \mathrm{SBA}-15$ system presented in Figure 7c corroborates the SAXS, TEM and APT findings (reported above) that $\mathrm{Pt}$ nanoparticles and $\mathrm{PtO}_{2}$ are present in this sample. Even though the concentration of the ${ }^{195} \mathrm{Pt}$ nucleus on the SBA15 surface is low, the frequency sweep experiment using the ATMA probe and the VOCS spectral accumulation method (50 kHz acquisition intervals) is sensitive enough to detect these $\mathrm{Pt}$ species. From a direct comparison with 5 $\mathrm{nm}$ Pt nanoparticles supported on carbon black and with well-ordered $\mathrm{PtO}_{2}$ as shown in Figure 7c, enough spectral features are discernible to clearly identify these Pt metal and Pt oxide components. A previous ${ }^{195} \mathrm{Pt}$ NMR study of Pt metal nanoparticles has demonstrated that the very broad ${ }^{195} \mathrm{Pt}$ static lineshape $(\sim 3.2 \mathrm{MHz}$ linewidth) can be analysed by the core-shell model, and estimates of the nanoparticle size can be attempted.52 The lack of a narrow and discernible feature at a Knight shift of $-35350 \mathrm{ppm}$ representing bulk Pt metal, and with intensity still present from the core-shell Knight shifts in the range of -30000 $-35000 \mathrm{ppm}$, it can be estimated that the Pt nanoparticle sizes in $\mathrm{Pt}_{8} \mathrm{Zn}_{2} / \mathrm{SBA}-15$ are in the $2-5 \mathrm{~nm}$ range. These estimates of dimension are consistent with the nanoparticle dimensions derived by SAXS and TEM methods. From the intensities measured in this ${ }^{195} \mathrm{Pt}$ static NMR data it can be observed that comparable amounts of diamagnetic $\mathrm{PtO}_{2}$ accompany the $\mathrm{Pt}$ nanoparticle formation. This is likely to form on the exterior of the Pt nanoparticles that form in the $2-5 \mathrm{~nm}$ range; the $\mathrm{Zn}$ that decorates the $\mathrm{Pt}$ nanoparticles and the $\mathrm{PtO}_{2}$ that coats these entities will effectively increase the intrinsic size of the deposited nanoparticles. 
Figure 7. a) ${ }^{29} \mathrm{Si}$, b) ${ }^{1} \mathrm{H}$ and c) ${ }^{195} \mathrm{Pt}$ NMR deconvoluted and simulated spectra

Atom Probe Tomography was performed on typical $\mathrm{Pt}_{2} \mathrm{Zn}_{8} / \mathrm{SBA}-15$ sample to identify the spatial distributions of the zinc compared to the platinum particles. Figure 8 shows 3 end-on atom maps from the green cross sections and 1 side-view atom map from the blue cross section, with each cross section $1 \mathrm{~nm}$ thick. The end-on maps indeed show that the $\mathrm{Zn}$ ions (yellow) are widely dispersed across the silica, and the platinum atoms cluster together forming spherical nanoparticles in the channels. The end-on images show the platinum particle size of around $4 \mathrm{~nm}$ which correlates with the size distribution expected from the TEM and SAXS results. It appears the distribution of zinc ions around the platinum particles is random, with some zinc ions adjacent to the platinum and others in regions without any platinum. This also indicates that the interaction of the zinc with the silica walls is much stronger than the interaction with the platinum. There are very small areas of zinc which are slightly more aggregated, and these could be rare clusters in the material. As there is no $\mathrm{Zn}$ crystallinity seen in the WAXS data and no long-range zinc interaction in the XAS indicating that these regions are rare and very small.

Figure 8. APT cross sections showing platinum (red) and zinc (yellow) species. Green cross sections show end-on images, looking down the SBA-15 channels and blue cross section shows the side-view image. Each cross section is $1 \mathrm{~nm}$ in thickness.

\section{Discussion}

The above characterization clearly indicates that small platinum containing nanoparticles can be formed in SBA15 channels without using surfactants or polymers by the described porous template method. The platinum precursors after reduction give primarily encapsulated metallic Pt nanoparticles with a narrow size distribution, smaller than the pore size inside the porous channels either by wet impregnation using purely $\mathrm{Pt}$ precursor or mixed $\mathrm{Pt}$ and $\mathrm{Zn}$ precursors (no blockage to the larger internal pores). Thus, this method appears to be suitable to prepare highly dispersed supported nanoparticles as catalysts. As stated, it is surprising to detect the absence of $\mathrm{Zn}$ containing nanoparticles for the same preparation over pure $\mathrm{Zn}$ precursors. Instead, the zinc forms homogeneously dispersed, but isolated, oxidic $\mathrm{Zn}-\mathrm{O}$ tetrahedra within the internal silica walls where no equivalent $\mathrm{Pt}$ species are anchored. This demonstrates the internal walls of the porous template can exert a significant influence on structure and morphology of nanoparticles growth therein. The reason for the propensity for zinc to anchor on the silica walls, compared to platinum, is not yet known, but this may be related to similar tetrahedral structure of silica for epitaxy-like anchoring of $\mathrm{Zn}$ species. In addition, zinc is more oxophilic than platinum53 which could lead to greater interaction and affinity between the internal silica surface than with the platinum, meaning that zinc preferentially disperses or wets to this support while platinum forms particles within the channels. This point is also demonstrated by the ${ }^{1} \mathrm{H}$ NMR studies which showed the high affinity for water molecules to lead to water clustering in the case of surfaces heavily modified with $\mathrm{Zn}$ species than that of $\mathrm{Pt}$ rich surfaces. Also, there are reciprocal modifications of the confined lattices for both encapsulated core-shell particles and host due to their structural and electronic interactions. In contrast to the model of $\mathrm{AgNi}$ system in $\mathrm{SBA}-15$ showing a clearly thermodynamic more stable Ni@Ag core shell particles of tunable dimensions (light element in core and heavy element in shell)54 which is adopted also by many other transition metal/metal oxide systems of $\mathrm{CuO}-\mathrm{Au}$ and $\mathrm{CuO}$ $\mathrm{Ag}, 55,56$ it is clearly not replicated in this system. It is noted that the immobilization of oxidic $\mathrm{Zn}-\mathrm{O}$ tetrahedral species on internal silica surface is somehow akin to the modified zeolite frameworks which may result from anchoring of two or three surface oxygens with terminal $\mathrm{OH}$ formed from $\mathrm{Zn}$ precursors dependent on surface acidity and impurities during their catalyst synthesis. The difference in spacing between $\mathrm{O}$ terminations over the internal amorphous silica surface and that of zinc oxide or hydroxide, can apparently avoid the extensive deposition of these phases on the wall, which maintains the oxidic $\mathrm{Zn}$ $\mathrm{O}$ tetrahedral species in isolation. It is shown from this study that such atomically dispersed zinc sources from surrounding internal walls can be used to decorate the formed Pt nanoparticle in close proximity after reduction. Temperature programmed reduction (TPR) shown in the supporting information (Figure S12) indicates that a significant co-reduction of $\mathrm{Zn}$ atoms from the modified silica walls is observed. This is shown from the enhanced $P t$ reduction peak indicating the partial reduction of the single $\mathrm{Zn}$ atoms to decorate the $\mathrm{Pt}$ nanoparticles57. Conventionally, decoration of supported precious metal nanoparticles with transition metal atoms is commonly achieved by exposing the metal nanoparticles on low surface area transition metal oxide supports, such as $\mathrm{Cu} / \mathrm{ZnO} 31$ or $\mathrm{Pd} / \mathrm{ZnO} 58$, to hydrogen gas with the formation of uncontrolled $\mathrm{CuZn}$ or $\mathrm{PdZn}$ content at the interface, through hydrogen spillover at elevated temperature. It is believed this new observation on the strong wall effects may lead to a development of new encapsulated single atom decorated metal catalysts dispersed in porous templates.

\section{Conclusions}

Although SBA-15 has been shown to promote the typical core-shell growth in bimetallic compounds such as $\mathrm{AgNi}$ under mild reduction, this does not translate into the PtZn system. The PtZn/SBA-15 catalysts show clearly segregated metallic behavior, with isolated $\mathrm{Zn}$ tetrahedra on the silica channel walls, and small Pt monometallic particles in the channels. The isolated $\left[\mathrm{ZnO}_{4}\right]^{6-}$ tetrahedra have no extended structure or crystallinity and do not appear in the microscopic images. The Pt particles on the other hand, are majority metallic, with a platinum oxide surface layer and are totally incorporated inside the channels of the SBA-15, not appearing on the surface of the support. The filing of the SBA-15 channels with $\mathrm{ZnPt}$ particles also leads to the alteration of the SBA-15 lattice structure. The use of SBA-15 as a support for formation of bimetallic nanoparticles is not trivial across various 
elemental compositions. In correlation with the previously reported core-shell synthesis we can see for the first time that the internal silica walls have a significant influence on the structure of the Pt particles formed inside. Zinc appears to form isolated sites across the silica while Pt is less attracted to the walls and forms the encapsulated particles in the channels. The interaction of isolated single atomic site zinc adjacent to platinum after reduction could lead to development of a new synthesis method for atomic decorated metal nanoparticles. This novel method for the synthesis of isolated $\mathrm{Zn}$ decoration on $\mathrm{Pt}$ nanoparticles is particularly advantageous due to its facile and reproducible nature. The use of a template also restricts the growth of the nanoparticles, leading to a maximum particle size of $8 \mathrm{~nm}$. However the synthesis is not predictable for alternative metal combinations, and as the particles are supported in the channels of the SBA-15, reagent diffusion could be an issue in liquid phase catalytic reactions.

\section{Experimental}

\section{Materials and Methods}

Platinum nitrate solution was sourced from Alfa Aesar. Zinc nitrate and mesoporous silica SBA-15 were bought from Sigma Aldrich along with ethanol (99\%) solvent. Characterization of SBA-15 such as BET has been reported previously. $^{31}$

\section{Synthetic Procedures}

PtZn(SBA-15) nanoparticles were synthesized without the use of surfactants using an incipient wetness technique. $2 \mathrm{~mL}$ pre-prepared platinum nitrate, zinc nitrate and ethanol solution was ground into $500 \mathrm{mg}$ SBA-15 using a pestle and mortar. After 10 minutes of grinding the powder was left to fully dry in air for at least 3 hours. The fully dried powder was calcined at $400{ }^{\circ} \mathrm{C}$ with a ramp rate of 2 ${ }^{\circ} \mathrm{C} / \mathrm{min}$ under nitrogen and then reduced at the same temperature under $5 \%$ hydrogen in argon for 4 hours. The sample was cooled to room temperature and ground for testing.

\section{Transmission Electron Microscopy}

Homogeneity of the metal dispersion inside the SBA-15 channels was examined by TEM using a JEOL $3000 \mathrm{~F}$ transmission electron microscope operated at $300 \mathrm{kV}$. TEM specimens were prepared by dispersing the dry catalyst powder in ethanol using sonication then pipetting $5 \mu \mathrm{l}$ of the sample dispersion onto holey-carbon coated copper grids. Secondary electron imaging and EDX mapping was performed to ensure the particles were inside the channels and to investigate the particle compositions. The samples were ground between two glass slides and dusted onto a holey carbon coated $\mathrm{Cu}$ TEM grid. The samples were examined in the JEM 2800 Transmission Electron Microscope using the following instrumental conditions: Voltage $(\mathrm{kV})$ 200; C2 aperture $(\mu \mathrm{m}) 30$ and 50; Dark-field (Z-contrast) imaging in scanning mode using an off-axis annular detector. Compositional analysis by X-ray emission detection in the scanning mode.

\section{Low Energy Ion Scattering}

High sensitivity-low energy ion scattering (HS-LEIS) was used to probe the change in composition with particle depth. The experiments were performed in a combined elevated-pressure reaction cell-ultrahigh vacuum (UHV) system. Sample preparation and characterization were conducted in the primary UHV chamber (base pressure, 2 $\times$ 10-9 Torr). HS-LEIS were measured by IONTOF Qtac100 using $20 \mathrm{Ne}+(5 \mathrm{keV})$ as ion source. The scattering angle was $145^{\circ}$.

\section{X-ray Absorption Spectroscopy}

$\mathrm{X}$-ray Absorption Spectroscopy, used to investigate the local structure and properties of the catalyst components, was undertaken at Diamond Light Source, beamline B18. Both the Pt L3- and Zn K-edges were measured where appropriate for each sample. The XAS measurements were conducted in the transmission geometry, in a step scan mode, using a silicon 311 double crystal monochromator. Typically, $150 \mathrm{mg}$ of sample was ground and pressed into a $13 \mathrm{~mm}$ diameter pellet. The $\mathrm{Pt}$ L3-edge was measured between 11336 and $12364 \mathrm{eV}$ and the $\mathrm{Zn} \mathrm{K}$-edge was measured between 9462 and 10512 eV. Figure S13 shows further information on the EXAFS fitting.

\section{Wide and Small Angle X-ray Scattering}

WAXS was collected at beamline I22 of the Diamond Light Source. Data collection was performed at $18 \mathrm{keV}$ using the Pilatus3-2M-DLS-L detector with a refined sample detector distance of $177 \mathrm{~mm}$ calibrated using a NIST 640c silicon standard reference material. Scans were performed ex-situ within $2 \mathrm{~mm}$ polycarbonate capillaries with total data acquisition time per sample of $1 \mathrm{~s}$. The collected 2D images were corrected for incident flux, transmission, and collection time, and reduced to 1D patterns using the DAWN software package59,60. An empty capillary was used to subtract the background from the data. A bare SBA-15 sample was also collected for comparative purposes. Data was processed with base-line subtraction to allow for direct comparison and peak fitting.

SAXS was collected at beamline $\mathrm{I} 22$ of the Diamond Light Source. Data collection was performed at $18 \mathrm{keV}$ using a Pilatus3-2M detector with a refined sample detector distance of $9.8 \mathrm{~m}$, calibrated using a silicon nitride grating with a $100 \mathrm{~nm}$ period. Scans were performed ex-situ within $2 \mathrm{~mm}$ polycarbonate capillaries with total data acquisition time per sample of $1 \mathrm{~s}$. The collected 2D images were corrected for incident flux, transmission, and collection time, and reduced to $1 \mathrm{D}$ patterns using the DAWN software package. An empty capillary was used to subtract the background from the data. A bare SBA-15 sample was also collected for comparative purposes. Peak fitting was conducted on the (200) reflection to extract the related lattice parameters of the SBA-15.

Solid State ${ }_{29} \mathrm{Si},{ }^{1} \mathrm{H}$ and ${ }^{195} \mathrm{Pt} \mathrm{NMR}$ 
Single pulse $29 \mathrm{Si}$ MAS NMR measurements were performed at $7.05 \mathrm{~T}$ using a Varian/Chemagnetics InfinityPlus spectrometer operating at a ${ }_{1} \mathrm{H}$ and $29 \mathrm{Si}$ Larmor frequencies $\left(v_{\mathrm{o}}\right)$ of 59.6 and $300.1 \mathrm{MHz}$, respectively. These experiments were performed using a Bruker $7 \mathrm{~mm} \mathrm{HX}$ probe which enabled a MAS frequency of $5 \mathrm{kHz}$ to be implemented. Pulse length calibration was performed on solid kaolinite from which a $\pi / 2$ pulse time of $4.5 \mu \mathrm{s}$ was measured. Quantitative measurements were achieved with a $\pi / 3$ pulse of $3.0 \mu$ s angle, together with a recycle delay of $240 \mathrm{~s}$. To aid the simulation and deconvolution through accurate identification of the speciation in the MAS NMR data, analogous ${ }_{1} \mathrm{H}-29 \mathrm{Si}$ cross-polarization MAS (CPMAS) measurements were undertaken using an initial ${ }_{1} \mathrm{H}$ $\pi / 2$ pulse of $4 \mu \mathrm{s}$, a contact time of $4 \mathrm{~ms}$, a $\mathrm{CP}$ ramp ranging from $75 \%$ and $100 \%$, and a recycle delay of $5 \mathrm{~s}$ were utilized. These data are shown in the Supporting Information (Fig. S7a). For both the single pulse MAS and CPMAS experiments heteronuclear ${ }_{1} \mathrm{H}$ decoupling was implemented during data acquisition. All ${ }_{29} \mathrm{Si}$ chemical shifts are reported against the IUPAC recommended primary ${ }_{29} \mathrm{Si}$ reference of $\mathrm{Me}_{4} \mathrm{Si}(\delta$ iso 0.0 ppm) via a solid kaolinite secondary reference at $\delta$ iso -92 ppm.44

Single pulse ${ }_{1} \mathrm{H}$ MAS measurements were performed at $9.4 \mathrm{~T}$ using a Bruker Avance HD spectrometer, operating at a ${ }_{1} \mathrm{H} v_{\mathrm{o}}$ of $398.8 \mathrm{MHz}$ and a MAS frequency of $12 \mathrm{kHz}$. These experiments were performed using a Bruker $4 \mathrm{~mm} \mathrm{HX}$ probe which enabled a MAS frequency of $12 \mathrm{kHz}$ to be achieved. A ${ }_{1} \mathrm{H} \pi / 2$ pulse time of $2.50 \mu \mathrm{s}$ was calibrated on solid $\alpha$-alanine, with a $\pi / 4$ pulse of $1.25 \mu$ s being implemented together with a recycle delay was $5 \mathrm{~s}$. All ${ }_{1} \mathrm{H}$ chemical shifts are reported against the IUPAC recommended primary $1 \mathrm{H}$ reference of $\mathrm{Me}_{4} \mathrm{Si}(\delta$ iso $0.0 \mathrm{ppm})$ via a solid $\alpha$-alanine secondary reference $\left(\mathrm{CH}_{3}\right.$ resonance) at $\delta$ iso $1.1 \mathrm{ppm} .44$

All ${ }_{195} \mathrm{Pt}$ static solid state NMR measurements were conducted on a Bruker Avance HD 7.05 T spectrometer ( $\left.v_{0}=64.5 \mathrm{MHz}\right)$ using a novel Bruker $7 \mathrm{~mm}$ static solids auto-tuning (ATMA) probe. The ATMA probe allows consistent automated tuning across the ${ }_{195} \mathrm{Pt}$ Knight/chemical shift range spanning $3.6 \mathrm{MHz}$, giving highly reproducible Variable Offset Cumulative Spectroscopy (VOCS)45,46,52 data which are comparable to our previously reported Field Sweep Fourier Transform (FSFT) method52. The VOCS method with automatic probe tuning stepped through the ${ }_{195} \mathrm{Pt}$ spectral range at $50 \mathrm{kHz}$ frequency intervals and applied a Hahn echo $(\pi / 2-\pi$ - acquire $)$ experiment which employed $4 / 8 \mu \mathrm{s} \pi / 2 / \pi$ pulse durations for data acquisition at each frequency step. A total of 250,000 transients were acquired per slice with a recycle delay of $0.1 \mathrm{~s}$ used for the fast relaxing Pt metal (Knight shifted) region, whereas the more diamagnetic $\mathrm{PtO}_{2}$ region used a longer recycle delay of $7 \mathrm{~s}$ with only 5000 transients being acquired at this higher frequency (downfield) region. Pulse time calibration and the ${ }_{195} \mathrm{Pt}$ shift referencing was performed on a Pt metal sample which served as secondary reference $\left(\delta_{\text {iso }}-35,350 \mathrm{ppm}\right)$ against the primary IUPAC reference of $1.2 \mathrm{M} \mathrm{Na} 2 \mathrm{PtCl}_{6}(\mathrm{aq})\left(\delta_{\text {iso }} 0.0 \mathrm{ppm}\right) .52$

Atom Probe Tomography
The APT specimens were prepared by the following procedure. A drop of SBA particle dispersion was placed onto a $\mathrm{Si}$ flat wafer, which was covered by a $200-\mathrm{nm}$ thick protective Cr layer61. Needle-shaped APT specimens were prepared from the Si flat sample by a site-specific lift-out procedure using a FEI Helios G4 CX focused ion beam (FIB)/scanning electron microscope. The APT experiments were conducted in a CAMECA LEAP 5000 XR instrument equipped with an ultraviolet laser with a spot size of $2 \mu \mathrm{m}$ and a wavelength of $355 \mathrm{~nm}$. The detection efficiency of this state-of-the-art microscope is $\sim 52 \%$. Data was acquired in laser pulsing mode at a specimen temperature of $60 \mathrm{~K}$, with a target evaporation rate of 3 ions per 1000 pulses, a pulsing rate of $125 \mathrm{kHz}$, laser pulse energy of $70 \mathrm{pJ}$. The APT data were reconstructed and analysed using the commercial IVAS 3.6. $14^{\mathrm{TM}}$ software.

\section{ASSOCIATED CONTENT}

Supporting Information. Supporting figures including TEM and EDX maps of series of catalysts, EXAFS, TPR and NMR. This material is available free of charge via the Internet at http://pubs.acs.org.

\section{AUTHOR INFORMATION}

\section{Corresponding Author}

*edman.tsang@chem.ox.ac.uk

\section{Author Contributions}

The manuscript was written through contributions of all authors. / All authors have given approval to the final version of the manuscript. / $\$$ These authors contributed equally.

\section{Funding Sources}

The financial support of two EPSRC CASE awards supported by Johnson Matthey are acknowledged.

\section{ACKNOWLEDGMENT}

The financial support of EPSRC and Johnson Matthey (JM) are acknowledged. The authors would also like to thank staff from Diamond Light Source, UK (B18 and I11) for access to beamtime under proposal numbers SP16316 and SM16583, Gregory Goodlet and Don Ozkaya for TEM/EDX images and Xiamen University for LEIS. JVH thanks the EPSRC, the University of Warwick and the Birmingham Science City Program for partial funding of the solid state NMR infrastructure at Warwick. The latter program accessed the Birmingham Science City Advanced Materials Project 1: Creating and Characterising Next Generation Advanced Materials, which derived support from Advantage West Midlands (AWM) and the European Regional Development Fund (ERDF).

\section{REFERENCES}

1. Gerland P, Raftery AE, Ševčíková H, Li N, Gu D, Spoorenberg T, Alkema L, Fosdick B K, Chunn J, Lalic N, Bay G, Buettner T, 
Heilig G K, Wilmoth J World Population Stabilization Unlikely this Century. Science 2014,346,234-7.

2. Shafiee S, Topal E. When will Fossil Fuel Reserves be Diminished? Energy Policy 2009,37,181-9.

3. Hodgson P. Nuclear Power and the Energy Crisis. Mod Age 2008,50,238.

4. Alayoglu S, Nilekar AU, Mavrikakis M, Eichhorn B. Ru-Pt Core-shell Nanoparticles for Preferential Oxidation of Carbon Monoxide in Hydrogen. Nat Mater 2008,7,333-8.

5. Zhang S, Metin Ö, Su D, Sun S. Monodisperse AgPd Alloy Nanoparticles and their Superior Catalysis for the Dehydrogenation of Formic Acid. Angew Chemie - Int Ed 2013,52,3681-4.

6. Balakrishnan N, Joseph B, Bhethanabotla VR. Effect of Platinum Promoters on the Removal of $\mathrm{O}$ from the Surface of Cobalt Catalysts: A DFT study. Surf Sci 2012,606,634-43.

7. Cybulskis VJ, Bukowski BC, Tseng HT, Gallagher J R, Wegener E, Kropf A J, Ravel B, Ribeiro F H, Greeley J, Wu Z, Miller J T. Zinc Promotion of Platinum for Catalytic Light Alkane Dehydrogenation: Insights into Geometric and Electronic Effects. ACS Catal 2017,7,4173-81.

8. Yarulin A, Berguerand C, Yuranov I, Crdenas-Lizana F, Prokopyeva I, KiwiMinsker L. Pt-Zn Nanoparticles Supported on Porous Polymeric Matrix for Selective 3-nitrostyrene Hydrogenation. J Catal 2015,321,7-12.

9. Liu G, Zeng L, Zhao ZJ, Tian H, Wu T, Gong J. Platinum-Modified $\mathrm{ZnO} / \mathrm{A} 12 \mathrm{O} 3$ for Propane Dehydrogenation: Minimized Platinum Usage and Improved Catalytic Stability. ACS Catal 2016,6,2158-62.

10. Lopez-Sanchez JA, Dimitratos N, Hammond C, Brett G L, Kesavan L, White S, Miedziak P, Tiruvalam R, Jenkins R L, Carley A F, Knight D, Kiely C J \& Hutchings $G$ J. Facile Removal of stabilizer-ligands from supported gold Nanoparticles. Nat Chem 2011,3,551-6.
11. Mishra PK, Saxena A, Rawat AS, Dixit PK, Kumar R, Rai PK. Surfactant-Free One-Pot Synthesis of Low-Density Cerium Oxide Nanoparticles for Adsorptive Removal of Arsenic Species. Environ Prog Sustain Energy 2017,37.

12. Pritchard J, Morris L, Walsh D, Sadasivan S, Ménard H, Bellabarba R M, Weller M T, Tooze R P. Synthesis of Well-Defined, Surfactant-Free Co3O4 Nanoparticles: The Impact of Size and Manganese Promotion on Co3O4 Reduction and Water Oxidation Activity. Catal Letters 2017,0,0.

13. Tao L, Zhao Y, Zhao Y, Huang S, Yang Y, Tong Q, Gao F. A Surfactant Free Preparation of Ultradispersed Surfaceclean Pt Catalyst with Highly Stable Electrocatalytic Performance. J Phys Chem Solids 2018,113,61-6.

14. Yin H, Tang H, Wang D, Gao Y, Tang Z. Facile Synthesis of Surfactant-free $\mathrm{Au}$ Cluster/graphene Hybrids for Highperformance Oxygen Reduction Reaction. ACS Nano 2012,6,8288-97.

15. Wang ZJ, Xie Y, Liu CJ. Synthesis and Characterization of Noble Metal (Pd, Pt, $\mathrm{Au}, \mathrm{Ag}) \quad$ Nanostructured Materials Confined in the Channels of Mesoporous SBA-15. J Phys Chem C 2008,112,1981824.

16. Kónya Z, Puntes VF, Kiricsi I, Zhu J, Ager $\mathrm{J}$ W, Ko M K, Frei $\mathrm{H}$, Alivisatos P, Somorjai G A. Synthetic Insertion of Gold Nanoparticles into Mesoporous Silica. Chem Mater 2003,15,1242-8.

17. Qiao B, Wang A, Yang X, Allard L F, Jiang Z, Cui Y, Liu J, Li J, Zhang T. Single-Atom Catalysis of CO Oxidation Using Pt1/FeOx. Nat Chem 2011,3,634-41.

18. Flytzani-Stephanopoulos M, Gates BC. Atomically Dispersed Supported Metal Catalysts. Annu Rev Chem Biomol Eng 2012,3,545-74.

19. Thomas JM, Saghi Z, Gai PL. Can a Single Atom Serve as the Active Site in Some Heterogeneous Catalysts? Top Catal 2011,54,588-94.

20. Heiz U, Sanchez A, Abbet S, Schneider 
WD. Catalytic Oxidation of Carbon Monoxide on Monodispersed Platinum Clusters: Each Atom Counts. J Am Chem Soc 1999,121,3214-7.

21. Turner M, Golovko VB, Vaughan $\mathrm{OPH}$, Abdulkin P, Berenguer-Murcia A, Tikhov M S, Johnson B F G, Lambert R M. Selective Oxidation with Dioxygen by Gold Nanoparticle Catalysts Derived from 55-atom Clusters. Nature 2008,454,981-3.

22. Kaden WE, Wu T, Kunkel WA, Anderson SL. Electronic Structure Controls Reactivity of Size-selected Pd Clusters Adsorbed on $\mathrm{TiO} 2$ Surfaces. Science 2009,326,826-9.

23. Nakamura, I., Nakano, H., Fujitani, T., Uchijima, T., Nakamura J. Evidence for a Special Formate Species Adsorbed on the $\mathrm{Cu}-\mathrm{Zn}$ Active Site for Methanol Synthesis. Surf Sci 1998,402-404,92-5.

24. J. Penzien, A. Abraham, J. A. van Bokhoven, A. Jentys, T. E. Müller, C. Sievers JAL. Generation and Characterization of Well-Defined $\mathrm{Zn}$ 2+Lewis Acid Sites in Ion Exchanged Zeolite BEA. J Phys Chem B 2004,108,4116-26.

25. Kozawa A. Ion-Exchange Adsorption of Zinc and Copper Ions on Silica. Nucl Chem 1961,21,315-24.

26. Connell G, Dumesic JA. The Generation of Bronsted and Lewis acid Sites on the Surface of Silica by Addition of Dopant Cations. J Catal 1987,105,285-98.

27. Takewaki T, Beck LW, Davis ME. Zincosilicate CIT-6: A Precursor to a Family of BEA-Type Molecular Sieves. J Phys Chem B 1999,103,2674-9.

28. Schweitzer NM, Hu B, Das U, Kim H, Greeley J, Curtiss L A, Stair P C, Miller J T, Hock A S. Propylene Hydrogenation and Propane Dehydrogenation by a Single-site Zn2+ on Silica Catalyst. ACS Catal 2014,4,1091-8.

29. Kolyagin YG, Ivanova II, Ordomsky V V, Gedeon A, Pirogov YA. Methane Activation over Zn-Modified MFI Zeolite : NMR Evidence for Zn - Methyl Surface
Species Formation. J Phys Chem C 2008,112,20065-9.

30. Orazov M, Davis ME. Catalysis by Framework Zinc in Silica-based Molecular Sieves. Chem Sci 2016,7,2264-74.

31. Li MM-J, Zheng J, Qu J, Liao F, Raine E, Kuo W C H, Su S S, Po P, Yuan Y, Tsang $\mathrm{S} C$ E. The Remarkable Activity and Stability of a Highly Dispersive Beta-brass $\mathrm{Cu}-\mathrm{Zn}$ Catalyst for the Production of Ethylene Glycol. Sci Rep 2016,6,20527.

32. Kang Y, Pyo JB, Ye X, Gordon TR, Murray CB. Synthesis, Shape Control, and Methanol Electro-oxidation Properties of $\mathrm{Pt}-\mathrm{Zn}$ Alloy and $\mathrm{Pt} 3 \mathrm{Zn}$ Intermetallic Nanocrystals. ACS Nano 2012,6,5642-7.

33. Ammari F, Lamotte J, Touroude R. An Emergent Catalytic Material: $\mathrm{Pt} / \mathrm{ZnO}$ Catalyst for Selective Hydrogenation of Crotonaldehyde. J Catal 2004,221,32-42.

34. $\mathrm{Yu} \mathrm{C}, \mathrm{Xu} \mathrm{H}, \mathrm{Ge} \mathrm{Q}, \mathrm{Li}$ W. Properties of the Metallic Phase of Zinc-doped Platinum Catalysts for Propane Dehydrogenation. J Mol Catal A Chem 2007,266,80-7.

35. Guda SA, Guda AA, Soldatov MA, Lomachenko K A, Bugaev A L, Lamberti C, Gawelda W, Bressler C, Smolentsev G, Soldatov A V, Joly Y. Optimized Finite Difference Method for the Full-Potential XANES Simulations: Application to Molecular Adsorption Geometries in MOFs and Metal-Ligand Intersystem Crossing Transients. J Chem Theory Comput 2015,11,4512-21.

36. Bunău O, Joly Y. Self-consistent Aspects of X-ray Absorption Calculations. J Phys Condens Matter 2009,21,345501.

37. Mei B, Becerikli A, Pougin A, Heeskens D, Sinev I, Grünert W, Muhler M, Strunk J. Tuning the Acid/base and Structural Properties of Titanate-loaded Mesoporous Silica by Grafting of Zinc Oxide. J Phys Chem C 2012,116,14318-27.

38. Mansour AN, Cook JW, Sayers DE. Quantitative Technique for the Determination of the Number of Unoccupied d-electron States in a Platinum Catalyst Using the L2,3 X-ray Absorption 
Edge Spectra. J Phys Chem 1984,88,2330 4.

39. Ichikuni N, Iwasawa Y. In Situ d Electron Density of Pt Particles on Supports by XANES. Catal Letters 1993,20,87-95.

40. Short DR, Mansour AN, Cook JW, Sayers DE, Katzer JR. X-Ray Absorption Edge and Extended X-ray Absorption Fine Structure Studies of PtTiO2 Catalysts. J Catal 1983,82,299-312.

41. Lytle FW, Wei PSP, Greegor RB, Via GH, Sinfelt JH. Effect of Chemical Environment on Magnitude of X-ray Absorption Resonance at LIIIedges. Studies on Metallic Elements, Compounds, and Catalysts. J Chem Phys 1979,70,4849-55.

42. Bressler I, Pauw BR, Thünemann AF, IUCr. $M c S A S$ : Software for the Retrieval of Model Parameter Distributions from Scattering Patterns. J Appl Crystallogr 2015,48,962-9.

43. Pauw BR, Pedersen JS, Tardif S, Takata M, Iversen BB, IUCr. Improvements and Considerations for Size Distribution Retrieval from Small-angle Scattering Data by Monte Carlo Methods. J Appl Crystallogr 2013,46,365-71.

44. Hung, Kai-T, Page, SJ, Gowsihan P, Shu C, Bobo Y, Hanna J V, Jones J R. Phosphate Content Affects Structure and Bioactivity of Sol-gel Silicate Bioactive Glasses. Int J Appl Glas Sci 2017,8,372-82.

45. Greasley SL, Page SJ, Sirovica S, Chen S, Martin R A, Riveiro A, Hanna J V, Porter A E, Jones J R. Controlling Particle Size in the Stöber Process and Incorporation of Calcium. J Colloid Interface Sci 2016,469,213-23.

46. Lin Z, Jones JR, Hanna J V, Smith ME. A Multinuclear Solid State NMR Spectroscopic Study of the Structural Evolution of Disordered Calcium Silicate Sol-gel Biomaterials. Phys Chem Chem Phys 2015,17,2540-9.

47. Macon ALB, Page SJ, Chung JJ, Amdursky N, Stevens M M, Weaver J V M, Hanna J V, Jones J R. A Structural and Physical Study of Sol-gel Methacrylate-silica
Hybrids: Intermolecular Spacing Dictates the Mechanical Properties. Phys Chem Chem Phys 2015,17,29124-33.

48. Xiang Y, Du J, Skinner LB, Benmore C J, Wren A W, Boyd D J, Towler M R. Structure and Diffusion of $\mathrm{ZnO}-\mathrm{SrO}-\mathrm{CaO}-$ Na2O-SiO2 Bioactive Glasses: A Combined High Energy X-ray Diffraction and Molecular Dynamics Simulations Study. RSC Adv 2013,3,5966-78.

49. Rosenthal AB, Garofalini SH. Structural Role of Zinc Oxide in Silica and SodaSilica Glasses. J Am Ceram Soc 2005,70,821-6.

50. McKeown DA, Muller IS, Buechele AC, Pegg IL. Local Environment of $\mathrm{Zn}$ in Zirconium Borosilicate Glasses Determined by X-ray Absorption Spectroscopy. J Non Cryst Solids 2000,261,155-62.

51. Grünberg $\mathrm{B}$, Emmler $\mathrm{T}$, Gedat $\mathrm{E}$, Shenderovich I, Findenegg G H, Limbach $\mathrm{H}$ H, Buntkowsky G. Hydrogen Bonding of Water Confined in Mesoporous Silica MCM-41 and SBA-15 Studied by $1 \mathrm{H}$ Solid-state NMR. Chem - A Eur J 2004,10,5689-96.

52. Rees GJ, Orr ST, Barrett LO, Fisher J M, Houghton J, Spikes G H, Theobald B R C, Thompsett D, Smith M E, Hanna J V. Characterisation of Platinum-based Fuel Cell Catalyst Materials Using 195Pt Wideline Solid State NMR. Phys Chem Chem Phys 2013,15,17195-207.

53. Kepp KP. A Quantitative Scale of Oxophilicity and Thiophilicity. Inorg Chem 2016,55,9461-70.

54. Li MM-J, Ye L, Zheng J, Fang H, Kroner A, Yuan Y, Tsang S C E. Surfactant-Free Nickel-silver Core@shell Nanoparticles in Mesoporous SBA-15 for Chemoselective Hydrogenation of Dimethyl Oxalate. Chem Commun 2016,52,2569-72.

55. Czaplinska J, Sobczak I, Ziolek M. Bimetallic $\mathrm{AgCu} / \mathrm{SBA}-15$ System: The Effect of Metal Loading and Treatment of Catalyst on Surface Properties. J Phys Chem C 2014,118,12796-810. 
56. Liu X, Wang A, Li L, Zhang T, Mou CY, Lee JF. Structural Changes of $\mathrm{Au}-\mathrm{Cu}$ Bimetallic Catalysts in CO Oxidation: In Situ XRD, EPR, XANES, and FT-IR Characterizations. J Catal 2011,278,28896.

57. Arroyo-Ramírez L, Chen C, Cargnello M, Murray CB, Fornasiero P, Gorte RJ. Supported Platinum-zinc Oxide Core-shell Nanoparticle Catalysts for Methanol Steam Reforming. J Mater Chem A 2014,2,19509-14.

58. Liao F, Wu X-P, Zheng J, Li M-J, Zeng Z, Hong X, Kroner A, Yuan Y, Gong X-Q,

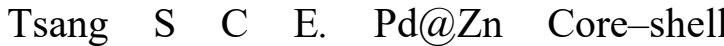
Nanoparticles of Controllable Shell Thickness for Catalytic Methanol Production. Catal Sci Technol 2016,6,7698-702.

59. Filik J, Ashton AW, Chang PCY, Chater P A, Day S J, Drakopoulos M, Gerring M W, Hart M L, Magdysyuk O V, Michalik S,
Smith A, Tang C C, Terrill N J, Wharmby $\mathrm{M}$ T, Wilhelm H. Processing Twodimensional X-ray Diffraction and Smallangle Scattering Data in DAWN 2. J Appl Crystallogr 2017,50,959-66.

60. Basham M, Filik J, Wharmby MT, Chang P C Y, El Kassaby B, Gerring M, Aishima J, Levik K, Pulford B C A, Sikharulidze I, Sneddon D, Webber M, Dhesi S S, Maccherozzi F, Svensson O, Brockhauser S, Náray G, Ashton A W. Data Analysis WorkbeNch (DAWN). J Synchrotron Radiat 2015,22,853-8.

61. Felfer P, Li T, Eder K, Galinski H, Magyar A P, Bell D C, Smith G D W, Kruse N, Ringer S P, Cairney J M. New Approaches to Nanoparticle Sample Fabrication for Atom Probe Tomography. Ultramicroscopy 2015,159,413-9. 
